\title{
Genetic alterations in presumptive precursor lesions of breast carcinomas
}

\author{
Michaela Aubele ${ }^{\mathrm{a}, *}$, Martin Werner ${ }^{\mathrm{b}}$ and Heinz Höfler ${ }^{\mathrm{a}, \mathrm{b}}$ \\ ${ }^{a}$ GSF-National Research Center for Environment and Health, Institute of Pathology Neuherberg, Germany \\ ${ }^{\mathrm{b}}$ Technische Universität München, Institute of Pathology, Munich, Germany
}

Received 1 March 2002

Accepted 24 May 2002

\begin{abstract}
The hypothetical multistep model of breast carcinogenesis suggests a transition from normal epithelium to invasive carcinoma via intraductal hyperplasia (without and with atypia) and in situ carcinoma. These presumptive precursor lesions are currently defined by their histological features, and their prognosis is imprecisely estimated from indirect epidemiological evidence.

Cytogenetic and molecular-genetic analysis of these lesions give evidence for an accumulation of various genetic alterations during breast tumorigenesis. Using immuno-histochemistry overexpression of the c-erbB-2 oncogene was found in ductal carcinoma in situ (DCIS), but not in atypical intraductal hyperplasia (AIDH) and intraductal hyperplasia (IDH). An expression of mutant p53 tumor suppressor gene as well as expression of cyclin D1 was identified in DCIS. In IDH lesions loss of heterozygosity $(\mathrm{LOH})$ at various loci could be identified, and comparative genomic hybridization (CGH) and fluorescence in situ hybridization (FISH) studies delivered evidence for DNA amplification on chromosomal region 20q13 in the early stage of IDH.

However, little is currently known about genetic alterations in those premalignant lesions, and the chronology of genetic alterations and histopathological changes during carcinogenesis is mainly undiscovered.
\end{abstract}

Figure 1 can be viewed in colour on http://www.esacp.org/acp/2002/24-2_3/aubele.htm.

\section{Introduction}

Breast cancer represents a significant worldwide public health problem. The introduction of mammographic screening has led to an increased detection of preinvasive alterations, particularly ductal carcinoma in situ (DCIS) and proliferative disease like IDH (intraductal hyperplasia) and AIDH (atypical intraductal hyperplasia). Those lesions are currently defined by their histological features, and their prognosis is imprecisely estimated from indirect epidemiologic evidence. Although considerable progress has been made in searching for the genetic events that underlie the progression of many malignancies, those involved in breast can-

\footnotetext{
*Corresponding author: Dr. M. Aubele, GSF-Forschungszentrum für Umwelt und Gesundheit, Institut für Pathologie, Ingolstädter Landstraße 1, 85764 Neuherberg, Germany. Fax: +49 893187 3360; E-mail: aubele@gsf.de.
}

cer development and progression are still poorly understood $[9,35]$.

Cytogenetic and molecular genetic analysis of breast precursor samples demonstrate that tumor development involves the accumulation of various genetic alterations including amplification of oncogenes and mutation or loss of tumor suppressor genes. The most investigated somatic genetic alterations in invasive carcinoma are amplifications of protooncogenes (e.g., cerbB-2) or gain of DNA on chromosomal band 11q13, mutation of the tumor suppressor gene p53, and loss of heterozygosity (LOH) from chromosomes or chromosome arms. There is increasing molecular biological evidence that DCIS is a direct precursor of invasive breast cancer. To date, however, much less molecular studies have been performed on the proliferative lesions IDH and AIDH, and only few of these studies tried to correlate their findings to certain histopatho- 
logical stages. Thus, little is known about the genetic alterations that characterize those lesions.

A greater understanding of how breast carcinoma develop and progress could lead to more directed forms of screening and therapy. It is, therefore, essential that the nature of these lesions can be biologically characterized and used to plan the most appropriate therapy. In the presence of new technologies like laserbased microdissection enabling precise sampling of cells from morphologically defined lesions, and amplification techniques for nucleic acid material, a definded attachment of genetic alterations to histopathological changes will become possible.

This review focuses on the most frequently identified genetic alterations in the presumptive precursor lesions of the breast, namely IDH, AIDH, and DCIS. It does not claim to cover all the data, but summarizes the most frequently identified cytogenetic and genetic alterations.

\section{Cytogenetics}

\subsection{Conventional cytogenetics}

After short-term culturing of IDC numerical changes (trisomy of chromosomes 7, 18, and 20, and loss of

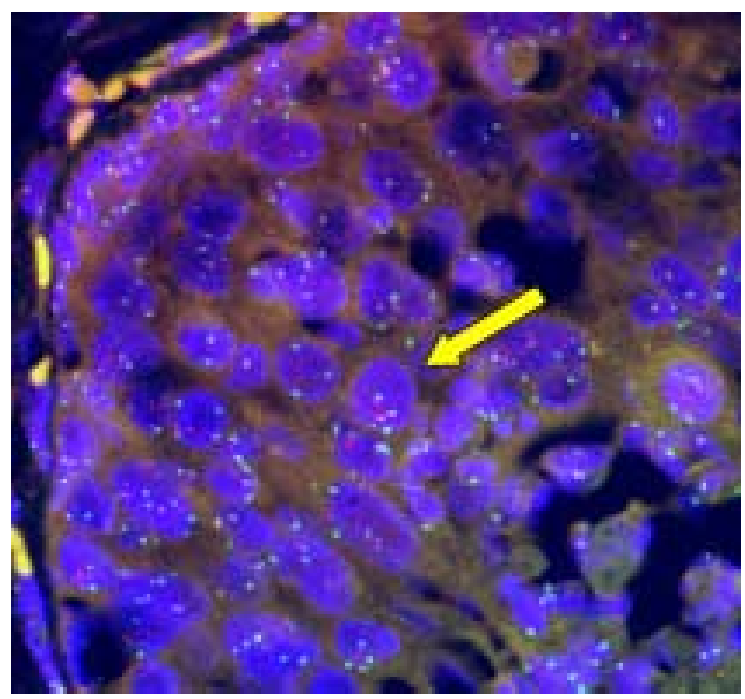

(a) chromosomes 17 and 19) and several structural rearrangements have been identified. However, due to methodological difficulties, conventional cytogenetic analysis of premalignant lesions of the breast has been carried out only in a small number of cases with ductal carcinoma in situ (DCIS), and, as with invasive ductal carcinoma (IDC), abnormalities of chromosomes 1 and 16 have been found [24].

\subsection{Fluorescence in situ hybridization (FISH)}

Fluorescence in situ hybridization (FISH) technique has been used to study chromosomal changes in DCIS and in proliferative disease. Using DNA probes to centromeric sequences of almost all chromosomes, polysomies of chromosomes 3, 10, and 17 and losses of chromosomes 1,16 , and 18 were frequently identified in DCIS [40]. In addition to polysomy of chromosome 17 the oncogene c-erbB-2, located on chromosome 17q11, was found amplified in DCIS [14,41]. In Fig. 1 increased signal counts for centromere 11 and Cyclin D1 are shown (Fig. 1(a)), as well as an increased signal frequency for centromere 17 and distinct clusters of the amplified c-erbB-2 (Fig. 1(b)) in the very same DCIS lesion (for methodology of ' $\mathrm{Se}$ quential FISH' see [49]). In proliferative lesions adjacent to carcinoma an increased frequency of chromo-

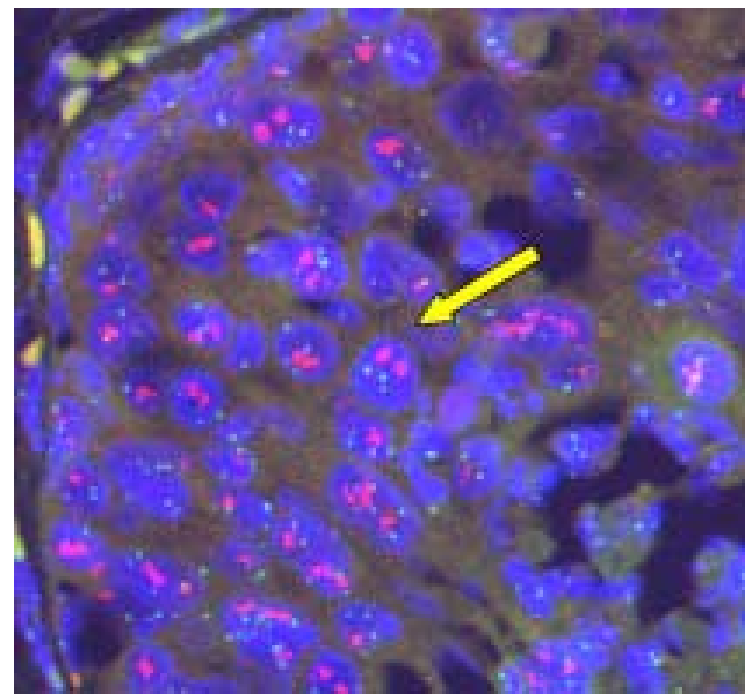

(b)

Fig. 1. 'Sequential FISH' on a DCIS lesion in a $5 \mu \mathrm{m}$ thick histological section, enabling detection of genetic alterations on the very same nuclei (arrows); (for methodology see [49]). (a) Cyclin D1 (red) and centromere 11 (green fluorescence) show both increased signal frequencies, demonstrating polysomy of the whole chromosome 11. (b) Increased signal counts are demonstrated for centromere 17 (green), indicating polysomy of the chromosome. Also an increased frequency was found for the oncogene c-erbB-2 (red fluorescence), which shows additionally distinct large clusters of the amplified oncogene. This figure can be viewed in colour on http://www.esacp.org/acp/2002/24-2_3/aubele.htm. 
Table 1

Most frequent chromosomal gains and losses identified by CGH. On the assumption of increasing histopathological stages from IDH to AIDH and to DCIS, chromosomal alterations occurring for the first time within that chronology are printed bold

\begin{tabular}{|c|c|c|c|}
\hline & Chromosomal alterations & $\begin{array}{c}\text { Total number } \\
\text { of cases }\end{array}$ & References \\
\hline IDH & no alteration & 14, & [10] \\
\hline $\begin{array}{l}\text { without evident } \\
\text { carcinoma }\end{array}$ & $-16 q-17 p$ & 9 & [23] \\
\hline IDH & no alteration & 2, & [17] \\
\hline $\begin{array}{l}\text { adjacent to } \\
\text { carcinoma }\end{array}$ & $+20 q,-13 q$ & 5 & [4] \\
\hline $\begin{array}{l}\text { AIDH } \\
\text { without evident } \\
\text { carcinoma }\end{array}$ & $-16 \mathrm{q},-17 \mathrm{p}$ & 9 & [23] \\
\hline $\begin{array}{l}\text { AIDH } \\
\text { adjacent to } \\
\text { carcinoma }\end{array}$ & $+\mathbf{3 p},+\mathbf{8 q},+\mathbf{1 5 q},+20 \mathrm{q},-13 \mathrm{q},-16 \mathrm{q}$ & 3 & [4] \\
\hline DCIS & & & \\
\hline $\begin{array}{l}\text { grade I } \\
\text { grade II }\end{array}$ & $\begin{array}{l}+\mathbf{1 q},+8 \mathrm{q},+\mathbf{1 1 q},+\mathbf{1 7 q},-9 \mathbf{p},-\mathbf{1 1 q},-13 \mathrm{q},-\mathbf{1 4 q},-16 \mathrm{q},-17 \mathrm{p} \\
+1 \mathbf{q},+\mathbf{6 q},+8 \mathrm{q},+11 \mathrm{q},+17 \mathrm{q},+\mathbf{1 9 q},+\mathbf{2 0 p},+20 \mathrm{q},+\mathbf{X q} \\
-\mathbf{2 q},-\mathbf{6 q},-\mathbf{8 p},-9 \mathrm{p},-11 \mathrm{q},-13 \mathrm{q},-14 \mathrm{q},-16 \mathrm{q},-17 \mathrm{p},-\mathbf{2 2}\end{array}$ & 181 & $\begin{array}{l}{[4,7} \\
11,12 \\
23,29\end{array}$ \\
\hline grade III & $\begin{array}{l}+1 \mathrm{q},+3 \mathbf{p p},+\mathbf{5 p},+6 \mathrm{q},+\mathbf{6 p},+\mathbf{7 q},+8 \mathrm{q},+\mathbf{1 0 q},+11 \mathrm{q},+\mathbf{1 4 q} \\
+\mathbf{1 5 q},+\mathbf{1 6},+17 \mathrm{q},+19 \mathrm{q},+20 \mathrm{p},+20 \mathrm{q},+\mathbf{2 1 q},+\mathbf{2 2 q},+X \mathrm{q} \\
-2 \mathrm{q},-\mathbf{4 q},-\mathbf{5 q},-6 \mathrm{q},-8 \mathrm{p},-9 \mathrm{p},-11 \mathrm{q},-13 \mathrm{q},-14 \mathrm{q},-16 \mathrm{q} \\
-17 \mathrm{p},-22\end{array}$ & & $\begin{array}{c}32,48 \\
50]\end{array}$ \\
\hline
\end{tabular}

some 1 was identified in intraductal hyperplasia (IDH) and - with increasing frequency - in adjacent atypical intraductal hyperplasia (AIDH) and DCIS [17].

Although several FISH studies have attempted to identify genetic alterations responsible for breast tumorigenesis and progression no specific chromosomal alteration could yet be attached to certain histopathological stages.

\subsection{Comparative genomic hybridization (CGH)}

Comparative genomic hybridization $(\mathrm{CGH})$ technique is a cytogenetic assay, which allows for an overview of DNA sequence copy numbers in a single hybridization. CGH studies within the last years delivered heterogeneous results for IDH lesions [5]. Losses on $16 \mathrm{q}$ and $17 \mathrm{p}$ have been identified in $\mathrm{DH}$ lesions without evident carcinoma [23], whereas no alterations were found in lesions of corresponding histopathology [10]. IDH lesions adjacent to carcinoma repeatedly show gain on chromosome $20 \mathrm{q}$ and loss on $13 \mathrm{q}$ [4], although no alterations were reported by Boecker et al. [10] (Table 1). Further histopathological stages (AIDH, DCIS) were accompanied by increasing num- bers of chromosomal imbalances (Table 1). Comparison of aberrations identified in initial DCIS lesions also brought evidence, that most of alterations showed a high concordance with their ipsilateral recurrences, suggesting a clonal relation to their initial lesions [50].

CGH analysis on DCIS, described in several studies, have demonstrated a large number of chromosomal alterations including gains on 1q, 6q, 8q, 17q, 19q, 20q, and $\mathrm{Xq}$, and losses on 13q, 16q, 17p, and 22q [4,7,11, $12,23,29,32,50]$ (Table 1). Despite the unsettled pathways of breast carcinogenesis, most of these alterations resemble those identified in IDC, adding weight to the idea that DCIS is a direct precursor lesion of IDC.

\section{Molecular genetics}

Molecular genetic analysis of breast cancer samples suggest that the development of breast cancer is based on the accumulation of various genetic alterations [9]. These molecular abnormalities may be classified into two types: gain-of-function genetic events that activate proto-oncogenes by DNA mutation, chromosomal rearrangement or amplification, and loss-of-function de- 
fects reflecting putative tumor suppressor genes that have been inactivated by DNA mutation or gene deletion.

\subsection{Loss of heterozygosity ( $\mathrm{LOH})$}

Frequent loss of heterozygosity (LOH) at a certain chromosomal locus in tumorous DNA indicates that this might be the site of a so far unknown tumor suppressor gene (TSG). Since the introduction of microsatellite-based loss of heterozygosity methodology in the eighties there have been a large number of studies investigating allelic imbalance in breast tumors at a large number of chromosomal loci [34]. Some of the identified LOH's could be attached to already wellknown TSG (e.g., Rb1, NME1, DCC), however, most identified LOH could not yet be attached to the corresponding gene.

In DCIS, LOH was frequently identified at several loci on chromosomes 1 [39], 3p21 [38], 11q23 [31], and chromosomes $8 \mathrm{p}, 13 \mathrm{q}, 16 \mathrm{q}, 17 \mathrm{p}, 17 \mathrm{q}$, and $18 \mathrm{q}$ $[21,44,48]$. The highest rates of LOH in DCIS approach 50 to $80 \%$ and involve loci on chromosomes $16 q, 17 p$, and $17 q$, suggesting that altered genes in these regions may be important in the development of DCIS [2,21,48]. Among more than 100 genetic loci studied so far on chromosome 17 nearly all DCIS showed at least one LOH $[2,21,39,42,44]$. Comparing LOH pattern of DCIS lesions with and without adjacent IDC delivered substantially more $\mathrm{LOH}$ in the cancerous breasts at loci on $2 \mathrm{p}, 11 \mathrm{p}$, and 17q [2,42]. Eighty percent of the DCIS and $50 \%$ of the proliferative lesions (IDH, AIDH) shared their LOH patterns with invasive carcinomas from the same breast, strongly supporting a precursor relationship between these lesions and the cancers they accompany [13]. On AIDH lesions LOH have been identified frequently on $16 q, 17 p$, and 11q13 [33]. On chromosome 11p an increasing frequency of $\mathrm{LOH}$ was shown from $10-20 \%$ in IDH, $10-40 \%$ in AIDH, and from 20 to $70 \%$ in DCIS $[2,42]$.

Interestingly, one study noted that morphological normal ductal epithelium shared LOH for markers on $3 \mathrm{p}, 11 \mathrm{p}$, and $17 \mathrm{p}$ with closely adjacent IDC, while normal ducts farther away in the breast did not [18]. Using several microsatellite markers (on chromosomes 1, 2, $7,11,17,18$, and X) allelic imbalance was identified with high frequency in normal-appearing breast ducts [36]. LOH was also identified in normal cells from breast cancer cases as well as from reduction mammoplasty specimens also suggesting that genetic alterations probably occur very early in breast tumorigenesis before pathological detection [33].

\section{Oncogenes and tumor suppressor genes}

A large number of biological characteristics have been evaluated on premalignant lesions of the breast. Most of these studies have been small and have not been validated [2], with the exceptions of the p53 tumor suppressor gene and the oncogenes c-erbB-2 and CCND1 on chromosomal band 11q13. Other genes, not described here (e.g., oncogenes c-myc, fes, c-met, and tumor suppressor gene Rb1) may also play an important role in breast carcinogenesis (for review see [51]).

\subsection{Oncogenes}

The proto-oncogene c-erbB-2 - also called neu or HER2 - encodes for a transmembrane protein, which has homology with the epidermal growth factor receptor (EGFR). The c-erbB-2 oncogene, which was found amplified and/or overexpressed in $20-30 \%$ of IDC [2], has received attention because of its association with lymph node metastases, short relapse time, poor survival, and decreased response to endocrine and chemotherapy of breast cancer patients [2,35,43]. Studies of c-erbB-2 have mainly used FISH technique to identify amplification or immunohistochemistry (IHC) to detect overexpression of the oncogene, which both are highly correlated $[2,46]$. c-erbB-2 amplification and/or overexpression was observed on average in $30 \%$ of DCIS, however, varying directly with differentiation [2]. It was identified in a high proportion of DCIS of high nuclear grade (60-80\%) but was not common in the low nuclear grade forms [9,34]. The c-erbB-2 protein was identified rarely in AIDH $[2,14,25]$. Absence of c-erbB-2 overexpression in normal ducts and AIDH, and the relatively high level in DCIS suggests that c-erbB-2 alterations are an important event in early malignant transformation.

Cyclin D1 protein plays an important part in regulating the progress of the cell during the G1 phase of the cell cycle. The Cyclin D1 gene (CCND1) on chromosome 11q13 has been implicated in carcinogenesis. In clinical studies of invasive breast cancer, however, overexpression of cyclin D1 was found to be associated with oestrogen receptor expression and low histological grade, both markers for good prognosis [22]. Amplification of CCND1 occurred in about $20 \%$ of DCIS and was more commonly found in high grade than in low grade DCIS (32\% versus 8\%) [45]. The cyclin D1 protein was detected in $50 \%$ of cases, and high levels were more likely in low grade than in the interme- 
diate and high grade DCIS [45]. Increasing levels of cyclin D1 expression were recently described for IDH with 11-19\%, AIDH with 27-57\%, and for DCIS with $35-50 \%[25,53]$. Based on those studies cyclin D1 expression may be of importance to distinguish between AIDH and well differentiated DCIS, and, thus, may become an aid to the diagnosis of malignancy.

The amplification site on 20q13 is a common finding in IDC examined by CGH [6,30] or FISH analysis [47, 52]. This chromosomal region was shown to involve several distinct variably coamplified chromosomal segments [3]. The region $20 \mathrm{q} 13$, spanning $\geqslant 1 \mathrm{Mb}$, harbours several putative oncogenes. Analysis of the $1 \mathrm{Mb}$ region produced evidence for at least five genes [15], and a complex amplicon structure with two regions of recurrent amplification was elucidated more recently $[1,16]$. Together these studies revealed a complex amplicon structure suggesting the presence of at least two driver genes (ZNF217 and NABC1 (Novel Amplified in Breast Cancer-1)) [16].

Amplification on the $20 \mathrm{q} 13$ region was described to be associated with aggressive tumor behaviour [28,47]. It was - in addition to IDC - frequently identified in DCIS [7,20], and also in premalignant lesions IDH and AIDH [4,52]. Thus, amplification at that chromosomal site appears to be an early event in breast tumorigenesis.

\subsection{Tumor suppressor genes}

The consistently mutated tumor suppressor gene (TSG) in sporadic breast cancer is TP53 [9,19]. The P53 protein functions as a transcription factor, which is involved in the control of cell proliferation. An association between the presence of p53 mutations and aggressive features within breast carcinomas, e.g., lack of oestrogen receptor, high S-phase index and association with disease-free survival was described [51]. Most p53 mutations are missense point mutations resulting in an inactivated protein that accumulates to high levels in the cell nucleus [2,19].

In DCIS, p53 mutations were found with a frequency different among the three histologic grade categories being quite rare in low-grade DCIS, 5\% in intermediate-grade, and relatively common $(40 \%)$ in high-grade DCIS [19,51]. p53 mutations or p53 protein expression have not been demonstrated in AIDH or other benign proliferative disease [2,35].

\section{Expression profiling}

Gene expression profiling will be a powerful approach in the next years toward the molecular classification of cancer [27]. Recently, the feasibility and reproducibility of array technology on DCIS was demonstrated [37]. More than 100 changes in gene expression in DCIS were identified in comparison to control transcripts. Several genes, previously implicated in human breast cancer progression, demonstrated differential expression in DCIS, e.g., up-regulation of Lactoferrin (a marker of oestrogen stimulation), PS2 (a oestrogen-responsive marker), and SIX1 (a homeobox protein frequently up-regulated in metastatic breast cancer), and down-regulation of, e.g., oxytocin receptor. A method for identification of amplified putative target genes and their overexpression was demonstrated on breast carcinomas using cDNA and tissue microarrays [27].

Gene expression profiling is a new technology. Combined with laser-microdissection of the small presumptive precursor lesions and amplification techniques for RNA it may provide us a wealth of additional molecular data with quantification of gene expression in the different histopathological stages.

\section{Heterogeneity}

Most of the biological abnormalities responsible for development and progression of premalignant breast lesions are still unknown. Studies in the breast have been complicated by the morphological heterogeneity, as well as the extremely heterogeneous molecularbiological findings [5,8]. Biological heterogeneity was identified already by conventional cytogenetic in DCIS [26], and by FISH analysis, where topologically distinct regions of DCIS from individuals had unique genetic alterations [40]. Further evidence delivered CGH data, demonstrating heterogeneity in IDC and DCIS [6,12], as well as in proliferative lesions (IDH, AIDH) [5].

\section{Conclusion and future prospect}

Figure 1 can be viewed in colour on http://www. esacp.org/acp/2002/24-2_3/aubele.htm.

Premalignant lesions of the breast are very common and they are being diagnosed more frequently due to increasing public awareness and screening mammog- 
raphy. They are currently defined by their histological features. Far less is known about biological factors in preinvasive disease than in IDC, and, so far, no single factor appears to be particularly powerful in predicting the development of IDC.

Very little is currently known about the molecular events that characterize breast cancer precursor lesions. Using IHC known cancer-associated genes have been analysed in preinvasive breast lesions, e.g., overexpression of c-erbB-2 oncogene, which is common in DCIS but absent in AIDH and IDH [13]. High grade DCIS show more frequently expression of mutant p53 than low-grade DCIS. Also expression of cyclin D1 is higher in high-grade DCIS than in low-grade DCIS and AIDH [13].

Only a few DNA alterations have been detected at the early stage of IDH in breast tissue. Loss of heterozygosity $(\mathrm{LOH})$ at various loci has been shown in $0-15 \%$ of IDH cases without atypia in benign breast biopsies [34]. Contrary, IDH adjacent to IDC shared $\mathrm{LOH}$ with the invasive cancer at one or more loci in $37 \%$ of cases [42], suggesting a role for mutations of tumor suppressor genes in the development of IDH. So far, oncogene amplification has not been considered a very early step in breast cancer development [35]. However, DNA alterations like gain on 20q, as identified by $\mathrm{CGH}$ and FISH [4,52], let us suppose, that also oncogene amplifications are present in IDH.

Many attempts are made to identify critical genetic events responsible for the development and progression of breast cancer. The pathogenesis of breast cancer is considered to be a multistep process. Proliferative breast lesions are regarded as benign disorders, yet epidemiologic studies indicate that they are associated with a significantly increased risk of developing breast cancer. Based on such studies, one of the current models of breast tumorigenesis proposes that normal epithelium becomes proliferative (hyperplasia without and subsequently with atypia) and then, through an accumulation of molecular abnormalities, evolves into a carcinoma, initially ductal carcinoma in situ, followed by invasive ductal carcinoma. In contrast to this single progressional pathway a parallel progression from morphologically normal epithelium directly to advanced disease is supported [8]. Some molecular observations indicated that breast disease can potentially follow several different tumorigenic pathways resulting in a more complex picture of the disease. There is still much controversy about breast carcinogenesis and its morphologically recognizable precursors. One reason for this may be the heterogeneous character of breast disease, both, phenotypically as well as with respect to its molecular biology. Therefore, it is extremely difficult to establish a diagnostically and prognostically relevant tumorigenesis model. Further reason for the so far unsolved pathogenesis pathways may be caused by the methodological problems performing molecular genetic analysis on such small histopathological leasons.

The introduction of new technologies such as precise sampling by laser-microdissection, different techniques for amplification of nucleic acid material, and microarray techniques promises to enlighten at least some of the responsible genetic events and their attachment to corresponding histopathological features within the next years. These findings possibly will enhance our understanding of the molecular mechanisms of mammary tumorigenesis, and, thus, may lead to more directed forms of screening and therapy.

\section{References}

[1] D.G. Albertson, B. Ylstra, R. Segraves, C. Collins, S.H. Dairkee, D. Kowbel, W.L. Kuo, J.W. Gray and D. Pinkel, Quantitative mapping of amplicon structure by array CGH identifies CYP24 as a candidate oncogene, Nat. Genet. 25 (2000), 144146.

[2] D.C. Allred, S.K. Mohsin and S.A.W. Fuqua, Histological and biological evolution of human premalignant breast disease, Endocrine-Related Cancer 8 (2001), 47-61.

[3] S.L. Anzick, J. Kononen, R.L. Walker, D.O. Azorsa, M.M. Tanner, X.-Y. Guan, G. Sauter, O.-P. Kallioniemi, J.M. Trent and P.S. Meltzer, AIB1, a steroid receptor coactivator amplified in breast and ovarian cancer, Science 277 (1997), 965-968.

[4] M. Aubele, M. Cummings, A. Mattis, H. Zitzelsberger, A. Walch, M. Kremer, H. Höfler and M. Werner, Accumulation of chromosomal imbalances from intraductal proliferative lesions to adjacent in situ and invasive ductal breast cancer, Diagnostic Molec. Pathol. 9(1) (2000), 14-19.

[5] M. Aubele, M. Cummings, A. Walch, H. Zitzelsberger, J. Nährig, H. Höfler and M. Werner, Heterogeneous chromosomal aberrations in intraductal breast lesions adjacent to invasive carcinoma, Analyt. Cell. Pathol. 20(1) (2000), 17-24.

[6] M. Aubele, A. Mattis, H. Zitzelsberger, A. Walch, M. Kremer, P. Hutzler, H. Höfler and M. Werner, Intratumoral heterogeneity in breast carcinoma revealed by laser-microdissection and comparative genomic hybridization, Cancer Genet. Cytogenet. 110 (1999), 94-102.

[7] M. Aubele, A. Mattis, H. Zitzelsberger, A. Walch, M. Kremer, G. Welzl, H. Höfler and M. Werner, Extensive ductal carcinoma in situ with small foci of invasive ductal carcinoma: Evidence of genetic resemblance by CGH, Int. J. Cancer $\mathbf{8 5}$ (2000), 82-86.

[8] M. Aubele and W. Werner, Heterogeneity in breast cancer and the problem of relevance of findings, Analyt. Cell. Pathol. 19 (1999), 53-58. 
[9] M.W. Beckmann, D. Niederacher, H.-G. Schnürch, B.A. Gusterson and H.G. Bender, Multistep carcinogenesis of breast cancer and tumour heterogeneity, J. Mol. Med. 75 (1997), 429-439.

[10] W. Boecker, H. Buerger, K. Schmitz, I.A. Ellis, P.J. van Diest, H.-P. Sinn, J. Geradts, R. Diallo, C. Poremba and H. Herbst, Ductal epithelial proliferations of the breast: a biological continuum? Comparative genomic hybridization and highmolecular-weight cytokeratin expression patterns, J. Pathol. 195 (2001), 415-421.

[11] H. Buerger, E.C. Mommers, R. Littmann, R. Simon, R. Diallo, C. Poremba, B. Dockhorn-Dworniczak, P. van Diest and W. Boecker, Ductal invasive G2 and G3 carcinomas of the breast are the end stages of at least two different lines of genetic evolution, J. Pathol. 194 (2001), 165-170.

[12] H. Buerger, F. Otterbach, R. Simon, C. Poremba, R. Diallo, T. Decker, L. Riethdorf, C. Brinkschmidt, B. DockhornDworniczak and W. Boecker, Comparative genomic hybridization of ductal carcinoma in situ of the breast - evidence of multiple genetic pathways, J. Pathol. 187 (1999), 396-402.

[13] R.F. Chuaqui, Z. Zhuang, M.R. Emmert-Buck, L.A. Liotta and M.J. Merinop, Analysis of loss of heterozygosity on chromosome 11q13 in atypical ductal hyperplasia and in situ carcinoma of the breast, Am. J. Pathol. 150 (1997), 297-303.

[14] E.D. Coene, V. Schelfjout, R.A. Winkler, A.M. Schelfhout, N. Van Roy, M. Grooteclaes, F. Speleman and C.R. De Potter, Amplification units and translocation at chromosome 17q and c-erbB-2 overexpression in the pathogenesis of breast cancer, Virchows Arch. 430 (1997), 365-372.

[15] C. Collins, J.M. Rommens, D. Kowbel, T. Godfrey, M. Tanner, S.-I. Hwang, D. Polikoff, G. Nonet, J. Cochran, K. Myambo, K.E. Jay, J. Froula, T. Cloutier, W.-L. Kuo, P. Yaswen and S. Dairkee, Positional cloning of ZNF217 and NABC1: genes amplified at 20q13.2 and overexpressed in breast carcinoma, Proc. Natl. Acad. Sci. USA 95 (1998), 8703-8708.

[16] C. Collins, S. Volik, D. Kowbel, D. Ginzinger, B. Ylstra, T. Cloutier, T. Hawkins, P. Predki, C. Martin, M. Wernick, W.-L. Kuo, A. Alberts and J.W. Gray, Comprehensive genome sequence analysis of a breast cancer amplicon, Genome Res. 11 (2001), 1034-1042.

[17] M.C. Cummings, M. Aubele, A. Mattis, D. Purdie, P. Hutzler, H. Höfler and M. Werner, Increasing chromosome 1 copy number parallels histological progression in breast carcinogenesis, Br. J. Cancer 82 (2000), 1204-1210.

[18] G. Deng, Y. Lu, G. Zlotnikov, A.D. Thor and H.S. Smith, Loss of heterozygosity in normal tissue adjacent to breast carcinomas, Science 274 (1996), 2057-2059.

[19] S.J. Done, S. Eskandarian, S. Bull, M. Redston and I.L. Andrulis, p53 missense mutations in microdissected high-grade ductal carcinoma in situ of the breast, J. Natl. Cancer Inst. $\mathbf{9 3}$ (2001), 700-704.

[20] M. Fiche, H. Avet-Loiseau, C.M. Maugard, C. Sagan, M.-F. Heymann, M. Leblanc, J.-M. Classe, P. Fumoleau, F. Dravet, M. Mahe and B. Dutrillaux, Gene amplifications detected by fluorescence in situ hybridization in pure ductal breast carcinomas: relation to morphology, cell proliferation and expression of breast cancer-related genes, Int. J. Cancer 89 (2000), 403-410

[21] H. Fuji, R. Szumel, C. Marsh, W. Zhou and E. Gabrielson, Genetic progression, histological grade, and allelic loss in ductal carcinoma in situ of the breast, Cancer Res. 56 (1996), 52605265 .

[22] C.E. Gillett, A.H.S. Lee, R.R. Millis and D.M. Barnes, Cyclin D1 and associated proteins in mammary ductal carcinoma in situ and atypical ductal hyperplasia, J. Pathol. 184 (1998), 396-400.

[23] G. Gong, S. DeVries, K.L. Chew, I. Cha, B.-M. Ljung and F.M. Waldman, Genetic changes in paired atypical and usual ductal hyperplasia of the breast by comparative genomic hybridization, Clin. Cancer Res. 7 (2001), 2410-2414.

[24] M. Harrison, H.M. Magee, J. O'Loughlin, T.F. Gorey and P.A. Dervan, Chromosome 1 aneusomy, identified by interphase cytogenetics, in mammographically detected ductal carcinoma in situ of the breast, J. Pathol. 175 (1995), 303-309.

[25] S.C. Heffelfinger, R. Yassin, M.A. Miller and E.E. Lower, Cyclin D1, retinoblastoma, p53, and Her2/neu protein expression in preinvasive breast pathologies: correlation with vascularity, Pathobiology 68 (2000), 129-136.

[26] S. Heim, M.R. Teixeira, C.U. Dietrich and N. Pandis, Cytogenetic polyclonality in tumors of the breast, Cancer Genet. Cytogenet. 95 (1997), 16-19.

[27] M. Heiskanen, J. Kononen, M. Bärlund, J. Torhorst, G. Sauter, A. Kallioniemi and O. Kallioniemi, CGH, cDNA and tissue microarray analyses implicate FGFR2 amplification in a small subset of breast tumors, Analyt. Cell. Pathol. 22 (2001), 229234.

[28] J.J. Isola, O.-P. Kallioniemi, L.W. Chu, S.A.W. Fuqua, S.G. Hilsenbeck, C.K. Osborne and F.M. Waldman, Genetic aberrations detected by comparative genomic hybidization predict outcome in node-negative breast cancer, Am. J. Pathol. 147 (1995), 905-911.

[29] L.A. James, E.L.D. Mitchell, L. Menasce and J.M. Varley, Comparative genomic hybridisation of ductal carcinoma in situ of the breast: identification of regions of DNA amplification and deletion in common with invasive breast carcinoma, Oncogene 14 (1997), 1059-1060.

[30] A. Kallioniemi, O.-P. Kallioniemi, J. Piper, M. Tanner, T. Stokke, L. Chen, H.S. Smith, D. Pinkel and J.W. Gray and Waldman, Detection and mapping of amplified DNA sequences in breast cancer by comparative genomic hybridization, Proc. Natl. Acad. Sci. USA 91 (1994), 2156-2160.

[31] J. Koreth, P.B. Bethwaite and J.O.D. McGee, Mutation at chromsome 11q23 in human non-familial breast cancer: a microdissection microsatellite analysis, J. Pathol. 176 (1995), $11-18$.

[32] T. Kuukasjärvi, M. Tanner, S. Pennanen, R. Karhu, O.P. Kallioniemi and J. Isola, Genetic changes in intraductal breast cancer detected by comparative genomic hybridization, Am. J. Pathol. 150 (1997), 1465-1470.

[33] S.R. Lakhani, R. Chaggar, S. Davies, C. Jones, N. Collins, C. Odel, M.R. Stratton and M.J. O'Hare, Genetic alterations in 'normal' luminal and myoepithelial cells of the breast, J. Pathol. 189 (1999), 496-503.

[34] S.R. Lakhani, N. Collins, M.R. Stratton and J.P. Sloane, Atypical ductal hyperplasia of the breast: clonal proliferation with loss of heterozygosity on chromosomes $16 \mathrm{q}$ and $17 \mathrm{p}, \mathrm{J}$. Clin. Pathol. 48 (1995), 611-615.

[35] S.R. Lakhani, The transition from hyperplasia to invasive carcinoma of the breast, J. Pathol. 187 (1999), 272-278. 
[36] P.S. Larson, A. de las Morenas, L.A. Cupples, K. Huang and C.L. Rosenberg, Genetically abnormal clones in histologically normal breast tissue, Am. J. Pathol. 152 (1998), 1591-1598.

[37] V. Luzzi, V. Holtschlag and M.A. Watson, Expression profiling of ductal carcinoma in situ by laser capture microdissection and high-density oligonucleotide arrays, Am. J. Pathol. 158 (2001), 2005-2010.

[38] A. Maitra, I.I. Wistuba, C. Washington, A.K. Virmani, R. Ashfaq, S. Milchgrub, A.F. Gazdar and J.D. Minna, Highresolution chromosome $3 p$ allelotyping of breast carcinomas and precursor lesions demonstrates frequent loss of heterozygosity and a discontinuous pattern of allele loss, Am. J. Pathol. 159 (2001), 119-130.

[39] K.E. Munn, R.A. Walker and J.M. Varley, Frequent alterations of chromosome 1 in ductal carcinoma in situ of the breast, Oncogene 10 (1995), 1653-1657.

[40] D.S. Murphy, S.F. Hoare, J.J. Going, E.A. Mallon, D. George, S.B. Kaye, R. Brown, D.M. Black and W.N. Keith, Characterization of extensive genetic alterations in ductal carcinoma in situ by fluorescence in situ hybridization and molecular analysis, J. Natl. Cancer Inst. 87 (1995), 1694-1704.

[41] D.S. Murphy, P. McHardy, J. Coutts, E.A. Mallon, W.D. George, S.B. Kaye, R. Brown and W.N. Keith, Interphase cytogenetic analysis of erbB2 and topoII co-amplification in invasive breast cancer and polysomy of chromosome 17 in ductal carcinoma in situ, Int. J. Cancer 64 (1995), 18-26.

[42] P. O'Connell, V. Pekkel, S.A. Fuqua, C.K. Osborne, G.M. Clark and D.C. Allred, Analysis of loss of heterozygosity in 399 premalignant breast lesions at 15 genetic loci, J. Natl. Cancer Inst. 90 (1998), 697-703.

[43] M. Ozturk, S. Bolkent, S. Yilmazer, G. Kaner and H. Unal, Detection of c-erbB-2 mRNAs using dig-labelled oligonucleotide probe with in situ hybridisation in human breast carcinoma: comparison with immunohistochemical results, Analyt. Cell. Pathol. 16 (1998) 201-209.

[44] D.M. Radford, K.L. Fair, N.J. Phillips, J.H. Ritter, T. Steinbrueck and M.S. Holt, Allelotyping of ductal carcinoma in situ of the breast: deletion of loci on 8p, 13q, 16q, 17p and 17q, Cancer Res. 55 (1995), 3399-3405.

[45] J.F. Simpson, D.E. Quan, F. O'Malley, T. Odom-Maryon and P.E. Clarke, Amplification of CCND1 and expression of its protein product, cyclin D1, in ductal carcinoma in situ of the breast, Am. J. Pathol. 151 (1997), 161-168.

[46] A. Tannapfel, R. Kühn, H. Keßler and C. Wittekind, Expression of c-erbB2 oncogene product in different tumours and its standardised evaluation, Analyt. Cell. Pathol. 10 (1966), 149160.

[47] M.M. Tanner, M. Tirkkonen, A. Kallioniemi, J. Isola, T. Kuukasjärvi, C. Collins, D. Kowbel, X.Y. Guan, J. Trent, J.W. Gray, P. Meltzer and O.-P. Kallioniemi, Independent amplification and frequent co-amplification of three nonsyntetic regions on the long arm of chromosome 20 in human breast cancer, Cancer Res. 56 (1996), 3441-3445.

[48] C.B.J. Vos, N.T. ter Haar, C. Rosenberg, J.L. Peterse, A.-M. Cleton-Jansen, C.J. Cornelisse and M.J. van de Vijer, Genetic alterations on chromosome 16 and 17 are important features of ductal carcinoma in situ of the breast and are associated with histologic type, Br. J. Cancer 81 (1999), 14101418.

[49] A. Walch, K. Bink, P. Hutzler, K. Bowering, I. Letsiou, H. Zitzelsberger, H. Braselmann, H. Stein, H. Höfler and M. Werner, Sequential multilocus fluorescence in situ hybridization can detect complex patterns of increased gene dosage at the single cell level in tissue sections, Lab. Invest. 81 (2001), 1457-1459.

[50] F.M. Waldman, S. DeVries, K.L. Chew, D.H. Moore, K. Kerlikowske and B.-M. Ljung, Chromosomal alterations in ductal carcinomas in situ and their in situ recurrences, J. Nat. Cancer Inst. 92 (2000), 313-320.

[51] R.A. Walker, J.L. Jones, S. Chappell, T. Walsh and J.A. Shaw, Molecular pathology of breast cancer and its application to clinical management, Cancer and Metastasis Reviews 16 (1997), 5-27.

[52] M. Werner, A. Mattis, M. Aubele, M. Cummings, P. Hutzler and $\mathrm{H}$. Höfler, 20q13.2 amplification in intraductal hyperplasia adjacent to in situ and invasive cancer of the breast, Virchows Arch. 435 (1999), 469-472.

[53] X.L. Zhu, W. Hartwick, T. Rohan and R. Kandel, Cyclin D1 gene amplification and protein expression in benign breast disease and breast carcinoma, Mod. Pathol. 11 (1998), 10821088 


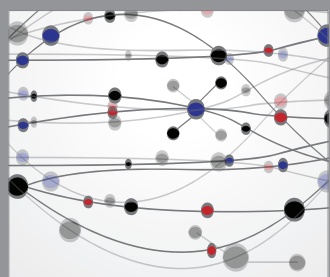

The Scientific World Journal
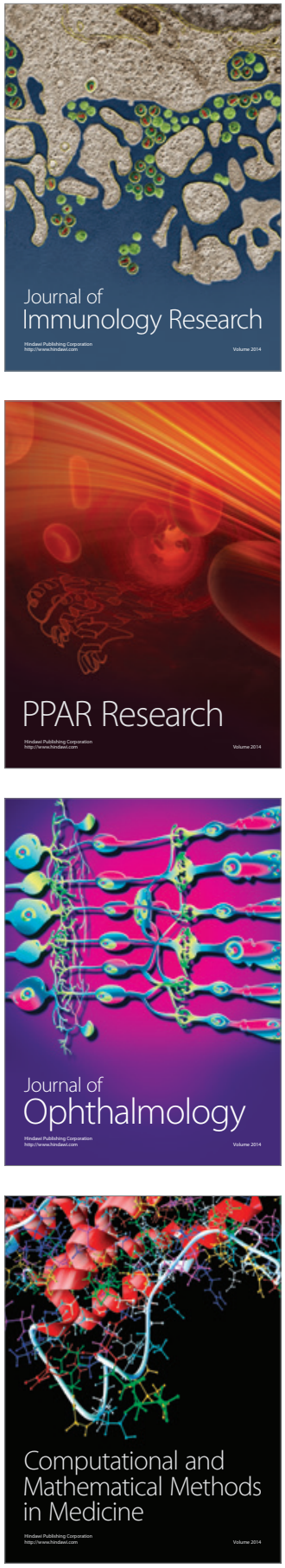

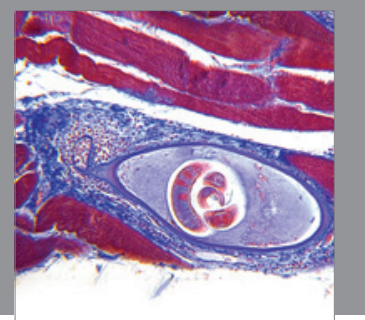

Gastroenterology

Research and Practice
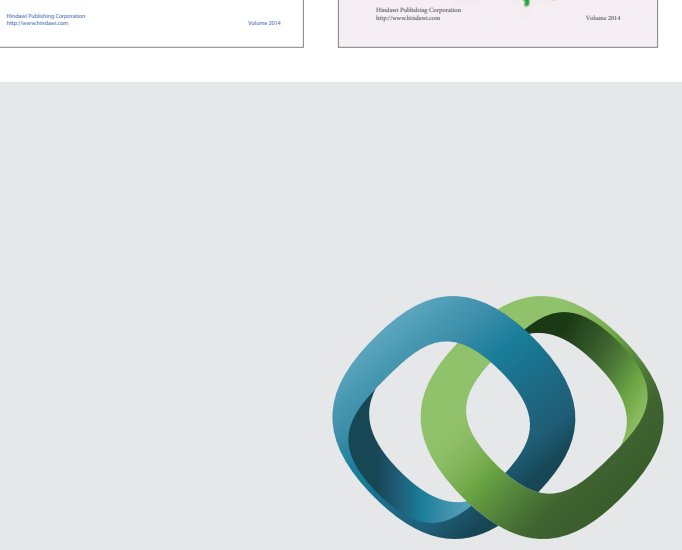

\section{Hindawi}

Submit your manuscripts at

http://www.hindawi.com
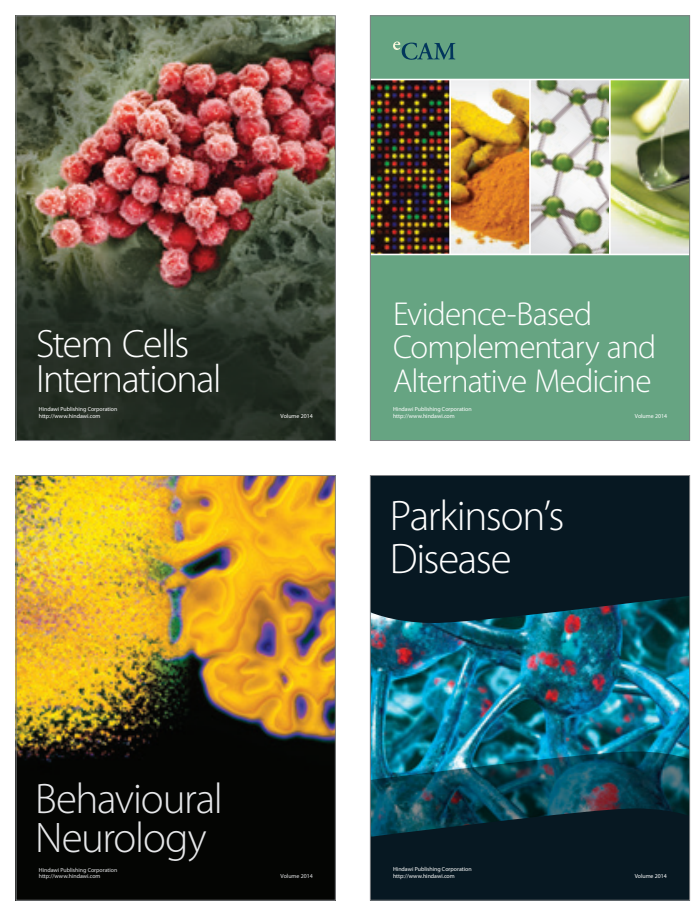

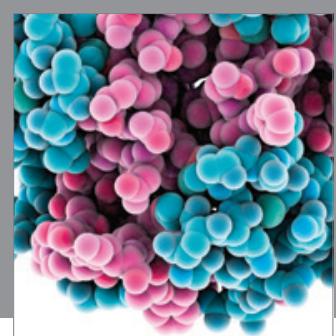

Journal of
Diabetes Research

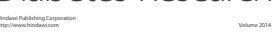

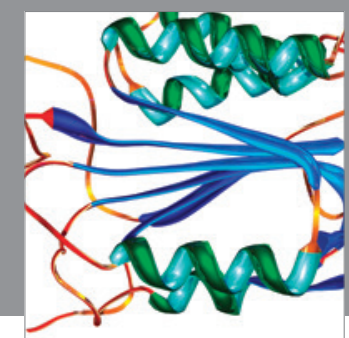

Disease Markers
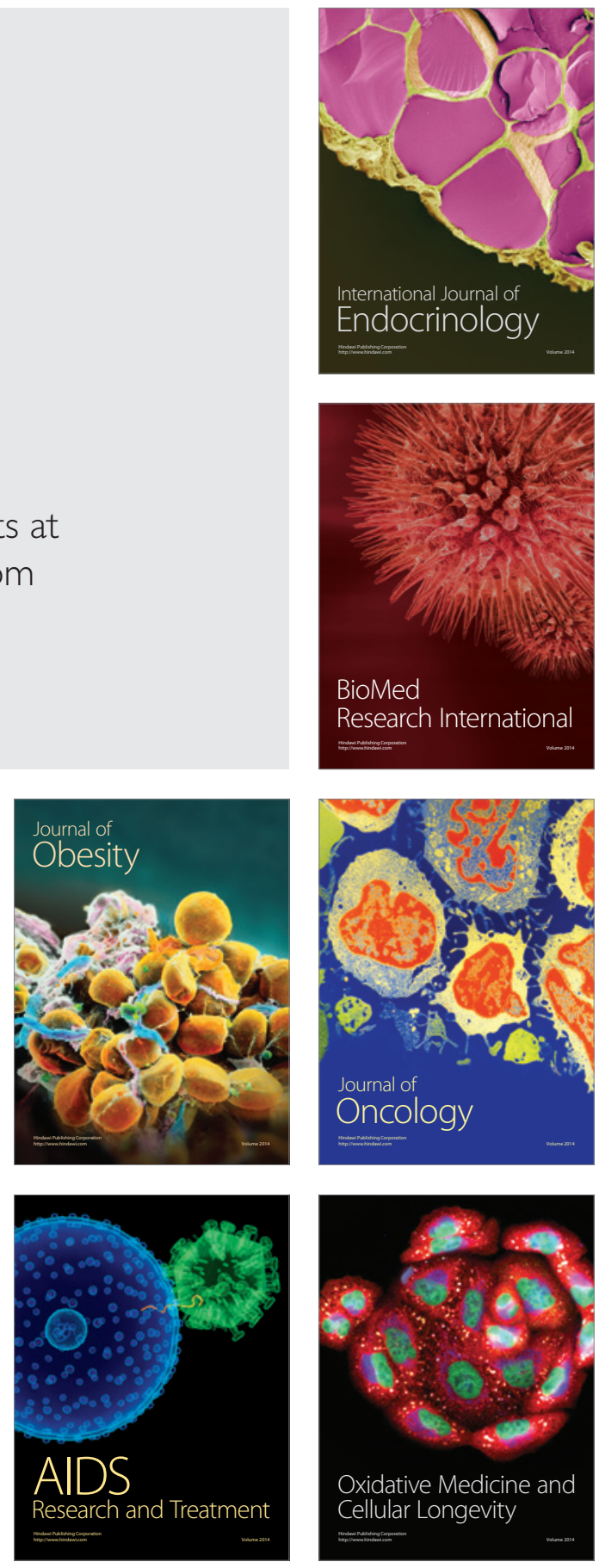